\title{
Design solutions overview of single-stage universal gear reducers
}

\author{
Milan Rackov ${ }^{1, *}$, Siniša Kuzmanović ${ }^{1}$, Ivan Knežević ${ }^{1}$, Maja Čavić $^{1}$, Marko Penčić ${ }^{1}$, Vladimir B. Algin ${ }^{2}$, \\ Victor E. Starzhinsky ${ }^{3}$, and Sergey V. Shil'ko ${ }^{3}$ \\ ${ }^{1}$ University of Novi Sad, Faculty of Technical Sciences, Trg Dositeja Obradovića 6, Novi Sad, Serbia \\ ${ }^{2}$ Joint Institute of Mechanical Engineering of National Academy of Sciences of Belarus, Akademicheskaya St. 12, 220072 Minsk, \\ Belarus \\ ${ }^{3}$ V.A. Belyi Metal-Polymer Research Institute of National Academy of Sciences of Belarus, Kirov St. 32-A, 246050 Gomel, Belarus
}

\begin{abstract}
Today, for almost all products, the appearance is very important. Thus, for example, the appearance of universal gear reducers was not given so much attention, but today there are many very interesting solutions of shape, colour and graphic design. It should have in mind that universal gear reducers have much complex construction comparing them with special gear reducers. In the same time, they have to provide different positions and way of mounting and different speeds with different powers (torques) at the output shaft. Particularly, it should be noticed, that within all universal gear reducers single-stage gear units are nowadays increasingly used because their gear ratio values are increased (values of gear ratio can go up to 15) so that these reducers largely cover most of the two-stage gear reducers with their gear ratio values, so thereby their exploitation is significantly increased. Single-stage gear reducers are very simple products, and today there is a large number of manufacturers of such product. However, their mounting dimensions and way of mounting are not defined by a standard, so there is a variety of units with different dimensions and way of mounting. Although, most manufacturers look up to dimensions of leading manufacturers (usually SEW) in order to ensure greater exchangeability of their gear units. It is interesting to note, that most manufacturers tend to adopt the design of housing that will be substantially different from competing solutions. The reason is probably to avoid the possibility of being accused of copying someone else's solution. However, there are manufacturers that retain almost identical housing design as a competing solution (probably they bought the licence or the solution is copied without permission). This paper considers only the design solutions of single-stage gear reducer in order to indicate the expected directions of their further development.
\end{abstract}

\section{Introduction}

Universal gear reducers can be divided in different ways $[1,2]$. The basic difference is now made according to the size of backlash into two types: the industrial reducers, which are most commonly exploited in practice (power transmissions) and low backlash reducers, with the backlash size less than 10 angular minutes, which are used only in precision mechanics, as movement transmissions. The article researches only industrial gear units. The further division is done according to the position of the gears on the cylindrical gear reducers and planetary reducers. In this paper, only industrial gear reducers will be considered, although today planetary reducers are increasingly used in places where at a slightly higher price it is possible to achieve large transmission ratios and small dimensions $[3,4,5]$. The cylindrical gear reducers can be divided into reducers with parallel and coaxial, or almost coaxial shafts. In this paper considers only single-stage reducers and they are made only as parallel shaft reducers.
The further division of these gear reducers can be made according to the mounting method with radial, axial and radial-axial mounting. According to the number of stages, reducers can be divided as single, two, three and multistage units, but this paper research only single-stage gear units. Depending on the way of connection between the reducer and the electric motor, gear units can be divided as classic with the input shaft and reducers with an adapter for IEC motors, when customer mounting electric motor or when reducers are delivered with IEC motor. Geared motors can be delivered with special reducer electric motor or with standard IEC motor. Depending on the size of the reducer, there are small (usually with axis height $\mathrm{h}$ $<100 \mathrm{~mm})$, medium $(100<\mathrm{h}<500 \mathrm{~mm})$ and large reducers $(\mathrm{h}>500 \mathrm{~mm})$, so that the size of the gear reducer can also have a certain impact on the final shape of the reducer $[1,5]$. Although, there is an interest that all gear units within one reducer family are identical to each other. So, in this paper, only medium-sized gears are considered, which are usually most required.

\footnotetext{
Corresponding author: racmil@uns.ac.rs
} 


\section{Problem description}

Single-stage reducers are exclusively manufactured in single-stage housings, although there are manufacturers who do not produce single-stage units at all. Different axis heights present a special problem, since the mounting ways are not the same in that case, the approaches of defining load capacity and gear ratio are different and appropriate materials used for manufacturing of gear reducers are not same, especially for smaller heights. By applying different measures, manufacturers of gear reducers bring out their own conceptual solution in order to differentiate their design from the competition solution or to achieve better characteristics. Manufacturers make the efforts to provide greater rigidity and stability of the entire gear unit by appropriate shape and weight distribution of gearbox housing. Axis height of the gear unit is one of the most important characteristics of gear reducers since it affects the value of gear ratio and load capacity, and sometimes it results in different conceptual designs. Axis heights of universal gear reducers are prescribed according to the standard row R20. Since this row is very dense, most manufacturers produce reducers with axis height in a standard row R10 (these numbers belong to the standard row R20). But soon they increased axis heights in order to increase gear ratio, and now reducers are produced with axis height in a standard row R20/2. In the area of the most used gearbox sizes, some manufacturers produce so-called intermediate sizes with the axis heights in row R20 [6,7]. In recent time, manufacturers of gear reducers try to achieve the same axis heights in order to ensure greater exchangeability of their gear units. This is especially important for smaller manufacturers, so they can offer their products instead of those of large manufacturers. This additionally means that they must have the same mounting dimensions, e.g. dimensions of the holes for base screws on the feet or flange and their position, etc.

Axis heights of single-stage gear reducers are presented in Table 1 [2]. Based on the axis heights presented in this table, it can be concluded that all manufacturers of single-stage gear reducers cover the interval of axis height from $63 \mathrm{~mm}$ till $112 \mathrm{~mm}$. Some manufacturers also offer smaller or larger heights.

As it can be seen no manufacturer fully respect the row R10 or R20/2, but they introduce additional heights, so-called intermediate sizes. For example, axis heights of 90,100 and $112 \mathrm{~mm}$ are often requested, so the large manufacturers produce gear units with this axis height in the row R20. Single-stage reducers with the minimum axis height of $50 \mathrm{~mm}$ are only manufactured by Lenze and Bonfiglioli. SEW produces single-stage gearboxes up to the height of $140 \mathrm{~mm}$ and Siemens-Flender and Leroy Somer up to $160 \mathrm{~mm}$.

Table 1. Axis heights of single-stage gear reducers for different manufacturers [2].

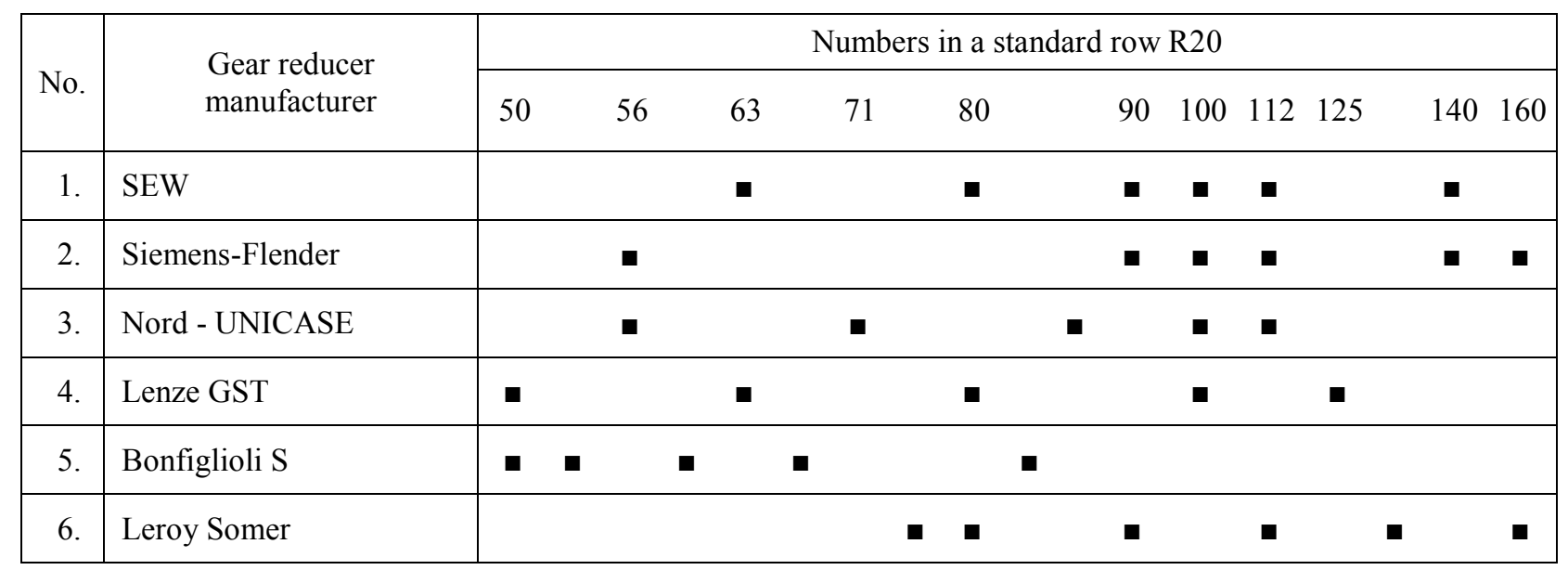

Gear reducer solution design should be realized in that way that only one bearing on output shaft receives the axial force. In that way, the cost of both bearings on

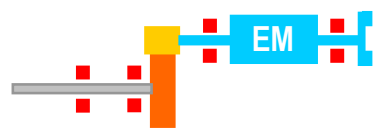

a)

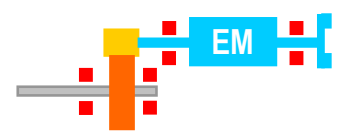

b)

Fig. 1. Possible conceptual solutions of single-stage universal gear reducer with special geared motor: a) output gear is overhung, b) output gear is between the bearings. the output shaft will be smaller, mounting and dismounting will be much simpler and the shaft is allowed to be expanded properly when heated. [7,8,9]

The helical gear should be positioned between the bearings, which ensure greater shaft rigidity. It is preferable the gear is positioned in the middle between the bearings to provide as even as possible the contact between two gear flanks. If it is not possible, the position of the gear should be realized in that way to ensure even contact of two flanks. Analyzing the characteristic conceptual solutions of single-stage universal gear units, only two conceptual solutions are possible: when output gear is overhang (Fig. 1-a) and when output gear is positioned between the bearings (Fig. 1-b).

At foot-mounted single-stage reducers, the pinion is positioned above the output gear, so that the large 
electric motor can be installed. In this way, the input shaft is at sufficient height relative to the base. The solution with the overhung output gear has larger dimensions and thus the weight of gear reducer (Fig. 2). Also, the deflection of this gear is slightly larger, but it is negligible because of the large diameter of the output shaft. However, this type of conceptual solution is much more often used than the solution with the gear between bearings (Fig. 3, 4).

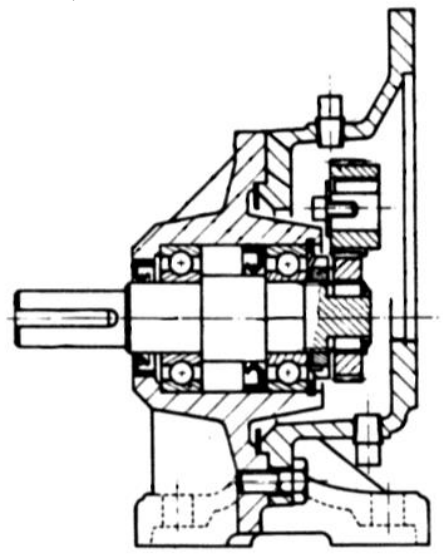

Fig. 2. The characteristic solution of foot-mounted single-stage gear reducer with the overhung output gear (Leroy Somer solution) [10].

During adopting the conceptual solution of gear reducer, mounting method and way of mounting elements should be considered. Also, this consideration must be given to the way of connecting gear reducer housing with housings of other units, or with the cover, electric motor, or adapter for IEC motors. Of course, this must take into account the minimum consumption of material, the lower the volume of machining and the sufficient strength and rigidity of the housing.

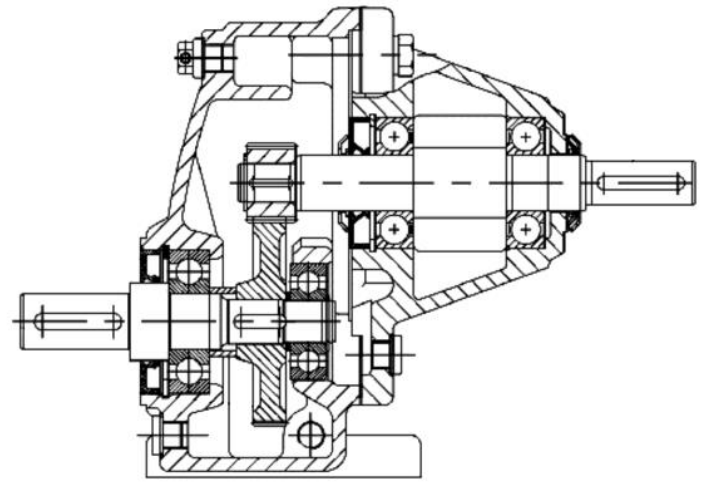

Fig. 3. The characteristic solution of foot-mounted single-stage gear reducer with the output gear between bearings (Nord solution) [8].

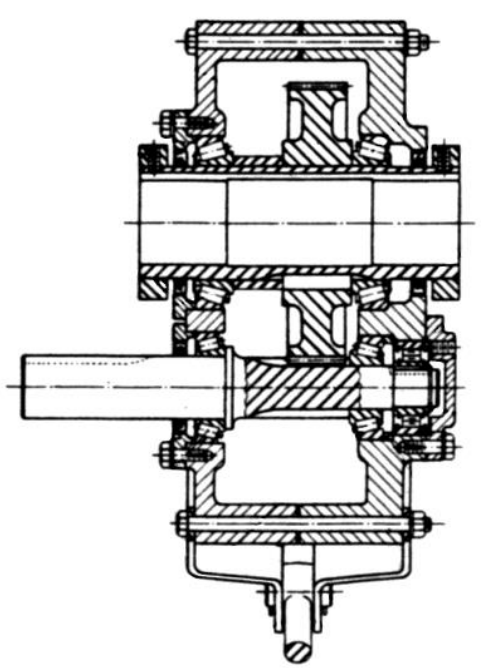

Fig. 4. The characteristic solution of shaft-mounted singlestage gear reducer with the output gear between bearings (Winsmith solution) [11].

Table 2. The way of mounting of one-housing single-stage universal gear reducers [2].

\begin{tabular}{|r|l|c|c|}
\hline No. & \multicolumn{1}{|c|}{$\begin{array}{c}\text { Gear reducer } \\
\text { manufacturer }\end{array}$} & & \\
\hline 1. & SEW & & \\
\hline 2. & Siemens-Flender & - & \\
\hline 3. & Nord - UNICASE & & \\
\hline 4. & Lenze GST & & \\
\hline 5. & Bonfiglioli S & & \\
\hline 6. & Leroy Somer & & \\
\hline
\end{tabular}

Universal single-stage gear reducers are produced as one-housing or two-housing units. However, the most usual way is monoblock housing produced as one-piece element. A large rear opening of single-stage reducer housing usually allows the installation of large gears.
When it is not possible, a special cover is assembled as a connection between housing and electric motor (Lenze solution [12], Fig. 5). In this case, there is no need to open housing from the top. 


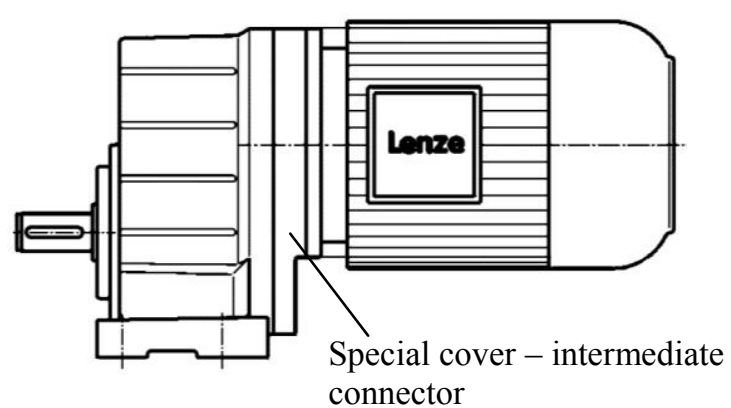

Fig. 5. The way of connection between housing and electric motor by using special cover - intermediate connector [12].

According to the mounting method, single-stage gear reducers can be produced in two ways: with or without special cover - intermediate connector (Table. 2). It is clear that only axial mounting of the parts is carried out in one-piece housing of single-stage gear reducer. It can be noticed from Table 2. that only two manufacturers produce gear units without an intermediate connector. All other manufacturers use this connector and in that way, they achieve higher gear ratio.

Based on the analyzed gearbox housings, it can be noticed that all manufacturers produce the housings from cast iron. Only two of them (Bonfiglioli S, Leroy Somer) use aluminium alloys as material for housings of the low axis heights of reducer $[13,10]$. In this way, they achieve a smaller weight of their gear units and thus better technical characteristics of their products.

\section{Analysis of housing design}

The housing design of single-stage gearbox depends most on the shaft arrangement and mounting method. According to this, there are gearboxes with horizontal (Fig. 6, 7, 8, 9, 10), with vertical (Fig. 11, 12) and with free shaft positions (Fig. 14, 15).

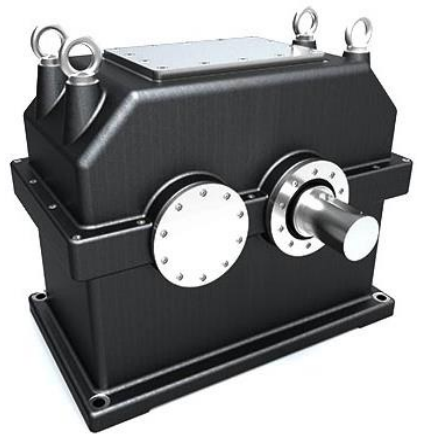

Fig. 6. The characteristic solution of foot-mounted single-stage gear reducer with the horizontal arrangement of the shafts (Kissling solution) [14].

Gear reducers with horizontal shaft position are usually manufactured with radial mounting and they present the old type of single-stage units. They passed through extremely intense shape development, from the usual and simple shapes, which insisted only on functionality and reduced material consumption (Fig. 6 and 7) to the very interesting contemporary forms, where great attention has been paid to the appearance of the gearbox (Fig. 9 and 10).

If the gear reducer is intended for operation in an environment with high ambient temperature, as well as the higher engine power is used and higher losses can be expected, the housing should be manufactured with ribs (Fig. 7) to increase the outer surface of the housing and improve heat dissipation. Also, housing with ribs is used for large gear unit to increase their rigidity.

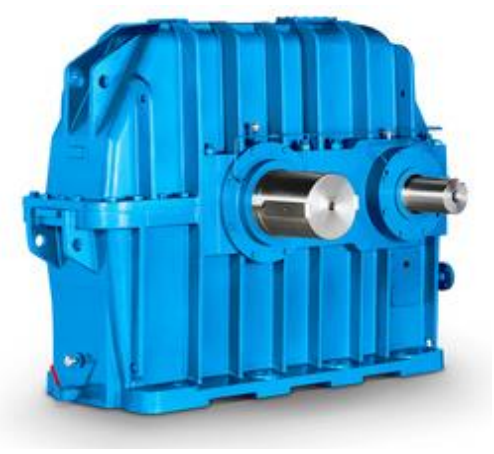

Fig. 7. The characteristic solution of foot-mounted single-stage gear reducer with the horizontal arrangement of the shafts and ribs at the housing (Flender solution) [15].

To simplify the gearbox production as much as possible, many manufacturers produce one-piece housings to avoid machining of large contact areas between two parts of the housing. They have to provide an opening for large gears, usually at the top of housing (Fig. 8) or on one of the front side (Fig. 9 and 10) which afterwards should be closed with a cover. With this approach, they significantly simplify the machining of the housings, although the assembling of such gear units is somewhat more complex.

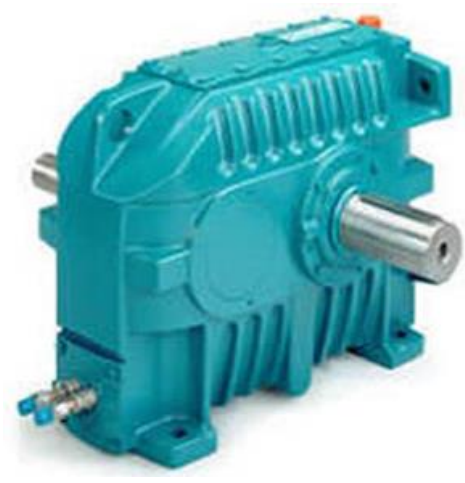

Fig. 8. The characteristic solution of foot-mounted single-stage gear reducer with the horizontal arrangement of the shafts (Hansen solution) [16].

Today, as stated above, basic attention is paid to aesthetic, i.e. product design. Modern solutions of single-stage universal gear reducer are recognized by simple and attractive form, slight shape transitions and somewhat higher material consumption. It is interesting to note that some manufacturers assemble single-stage gear reducers in the housings for two-stage gear units (cylindrical-bevel gear reducers) to increase the series of housing and thereby reduce production costs (Fig. 9 and $10)$. 


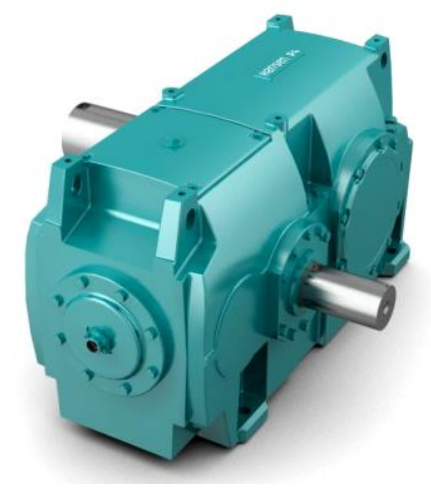

Fig. 9. The characteristic solution of foot-mounted single-stage gear reducer with the horizontal arrangement of the shafts (Hansen solution) [16].

In order to increase the versatility of their gear reducers, some manufacturers produce the housings with feet on all four sidewise surfaces. In this way, the gearbox can be mounted with horizontal shaft arrangement, but also in vertical shaft arrangement. The additional opening is added through which the gears are mounted and it is closed by a cover. In order to increase the versatility of this gearbox, an additional flange is created on the front surfaces of the housing (Fig. 10).

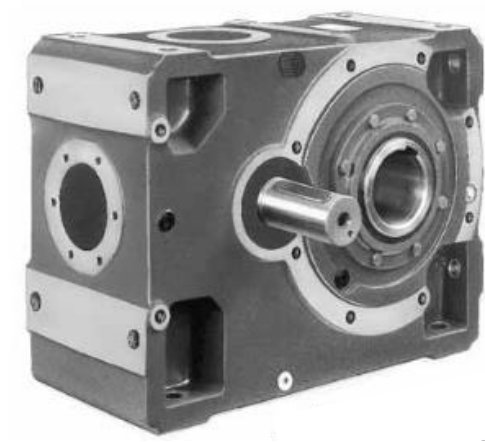

Fig. 10. The characteristic solution of single-stage gear reducer with both horizontal and vertical arrangement of the shafts (Rossi solution) [17].

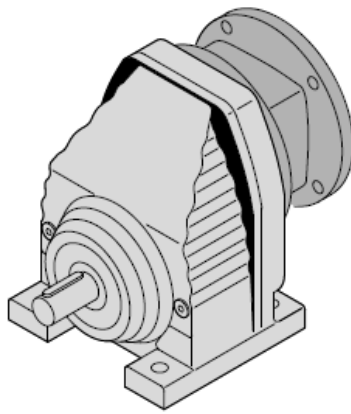

a)

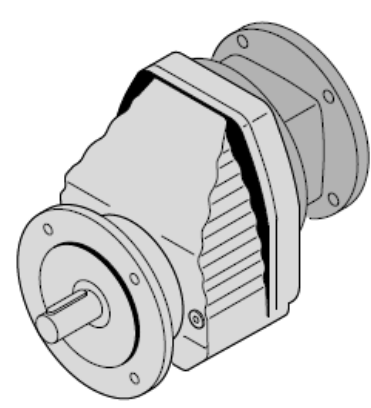

b)
Fig. 11. The characteristic solution of single-stage gear reducer with vertical shafts arrangement (Rossi solution): a) footmounted and b) flange-mounted [17].

Single-stage universal gear reducers with vertical shaft arrangement are today more common in practice. They are produced with a different way of connecting: foot-mounted gearbox (Fig. 11a), flange-mounted gearbox (Fig. 11b) and foot and flange-mounted gearbox (Fig. 12). Gear reducers with vertical shaft arrangement have a simpler machining processing, but assembling is a bit complicated.

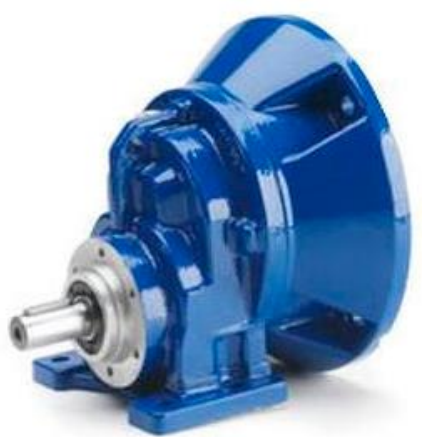

Fig. 12. The characteristic solution of single-stage gear reducer with vertical shafts arrangement foot and flange-mounted way (STM TEAM solution) [18].

Some manufacturers that produce gear reducers in small series, practice using an universal housing with feet or flange connected by screws.

The housings of single-stage gear reducers with free shaft arrangement (but also all other arrangements) are manufactured as rounded (Fig. 13), but also as squared (Fig. 14). When they are assembled with a hollow shaft, they are called shaft-mounted gear units. They are also complicated for manufacturing since they need to be machined in two large contact areas and then to be connected, centred and further machined. They are simple for axial mounting and almost all assembly is done outside the gearbox housing.

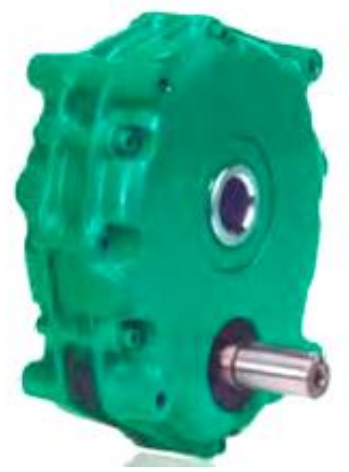

Fig. 13. The characteristic solution of single-stage gear reducer with free shaft arrangement (Leroy Somer solution) [10].

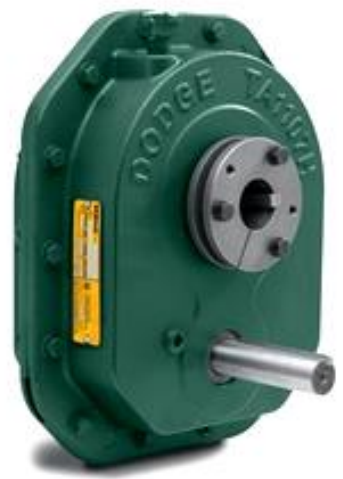

Fig. 14. The characteristic solution of single-stage gear reducer with free shaft arrangement (Dodge solution) [19]. 


\section{Solution analysis}

Variety wideness and way of mounting of single-stage gear reducer solutions depends on each manufacturer.
B3

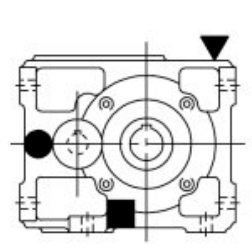

B8

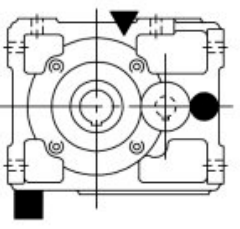

B6

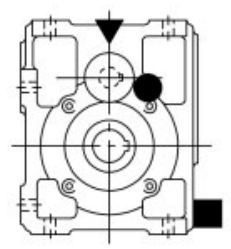

B7

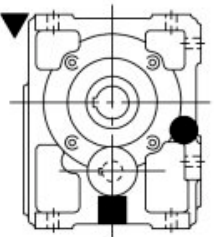

V5

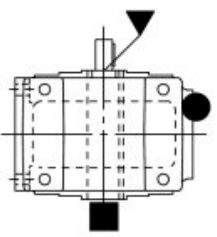

V6

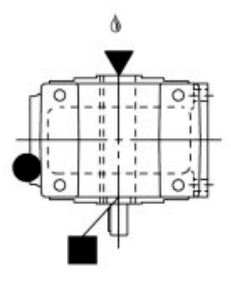

Fig. 15. The characteristic solutions of position and way of mounting of single-stage gear reducer (Rossi solution) [17].
Modern single-stage universal gear reducers with horizontal and vertical shaft arrangement are highly universal gear units, adapted for different shapes and mounting positions (Fig. 15).

Company NRW is one of the less known gearbox manufacturers and, besides other gear reducers, NRW produces single-stage gear units with vertical shaft arrangement. It produces the most complete gear reducer program (Fig. 16, 17, 18). NRW is one of the few manufacturers who produce foot-mounted single-stage gearboxes with an output shaft positioned both up and down (Fig. 16). The output shaft is very rarely positioned above the pinion since it often prevents installation of motor gear reducer on a flat surface. This manufacturer also produces foot and flange-mounted single-stage gear units for three different flange diameters, which is rarely required. It also produces flange-mounted gear reducers with different flange diameters that are connected with housing by screws (Fig. 17). NRW produces gear units with the classic input shaft and with the adapter for IEC motors with flanges B5 and B14. The design of the housing is quite complex, taking into account the cost savings of the material as well as the reinforcement of the housing. The form is simple and attractive (Fig. 18). [5]
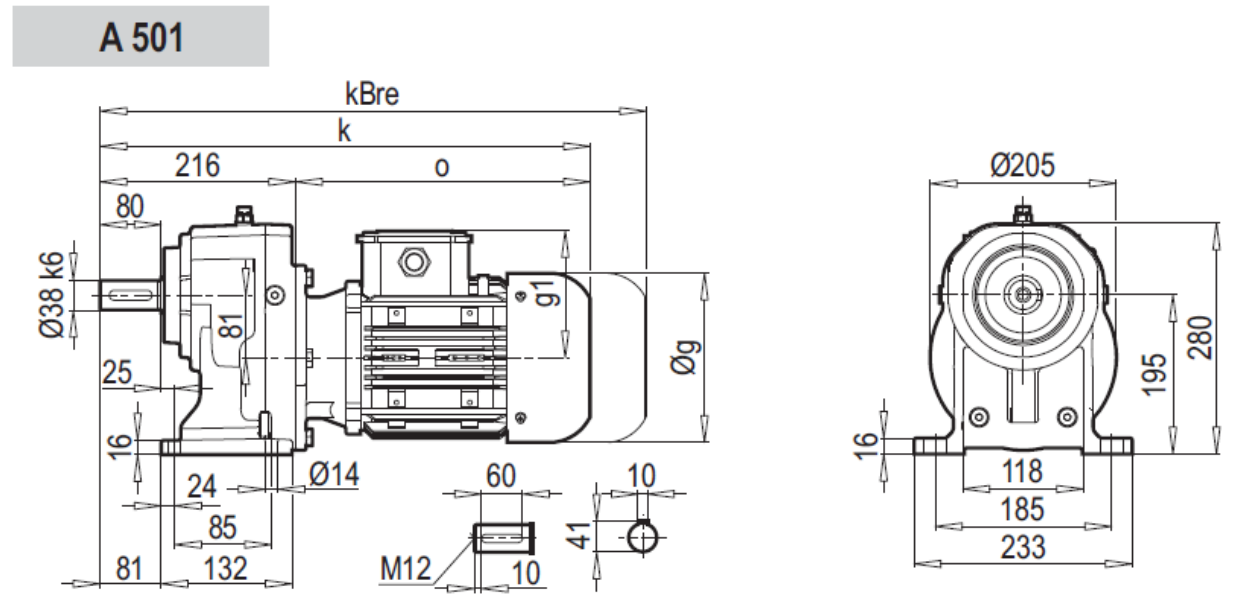

\section{AF-M 501}
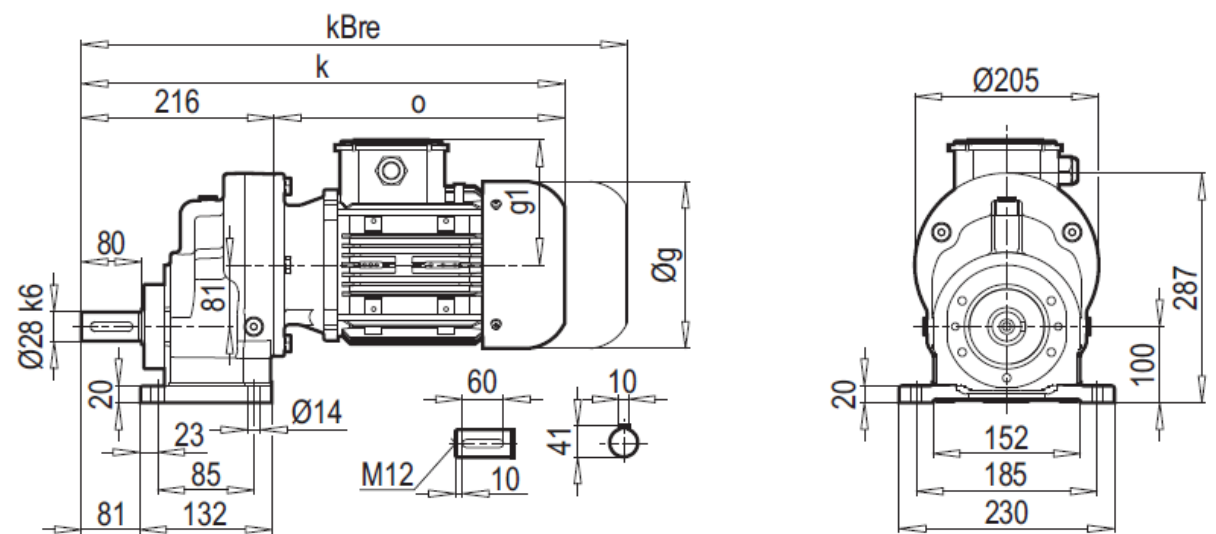

Fig. 16. Characteristic design solutions of single-stage gear reducer with output shaft positioned both up and down (NRW solution) [5]. 


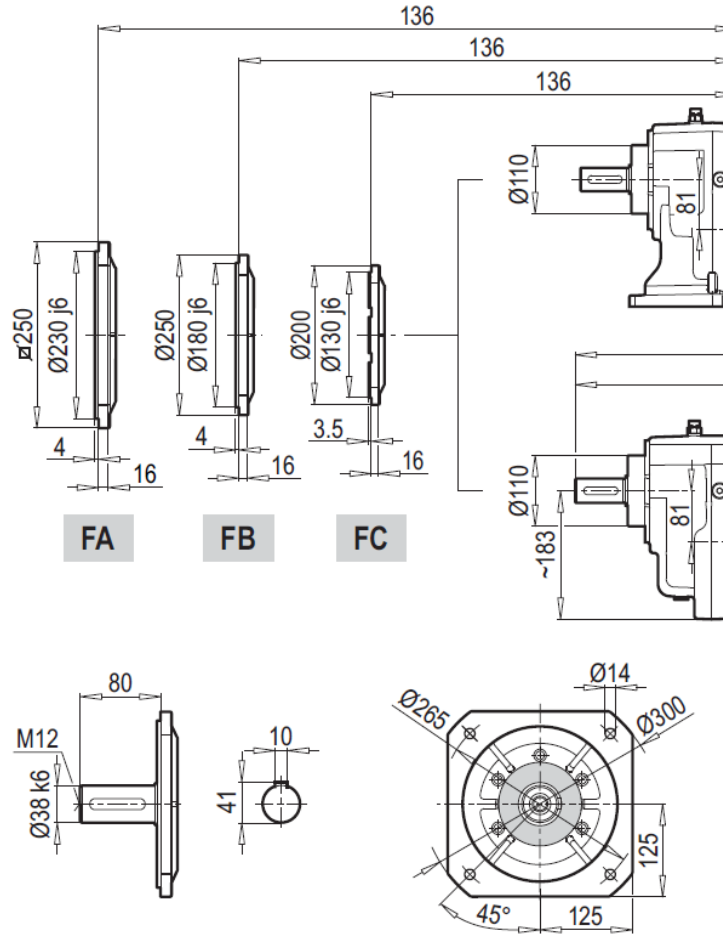

FA

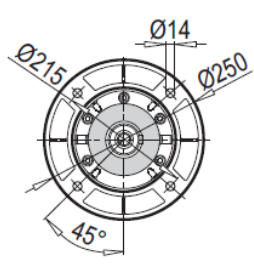

FB
AF 501

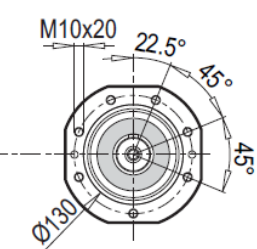

F 501

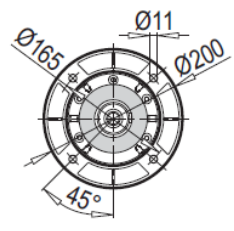

FC

Fig. 17. Characteristic design solutions of single-stage gear reducer with different flange diameters connected with housing by screws (NRW solution) [5].

A 501 PAM B5/B14

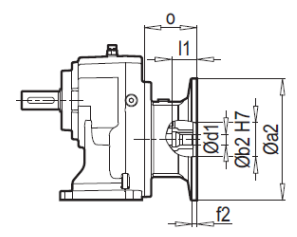

F 501 PAM B5/B14

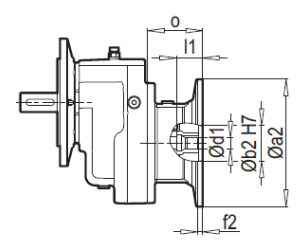

AF 501 PAM B5/B14

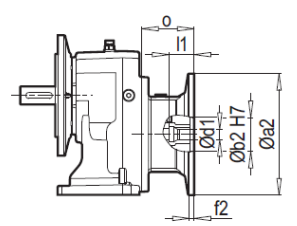

AF-M 501 PAM B5/B14

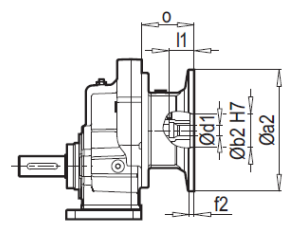

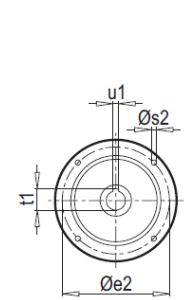
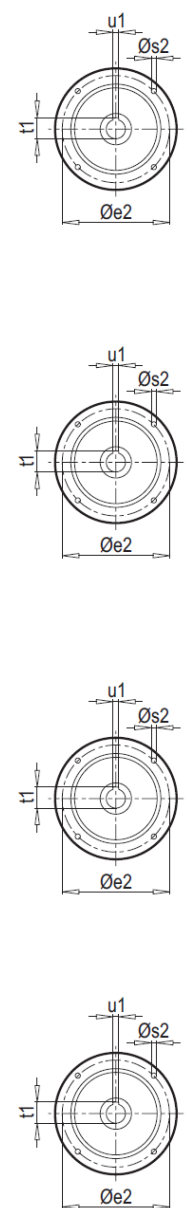

A 501 W
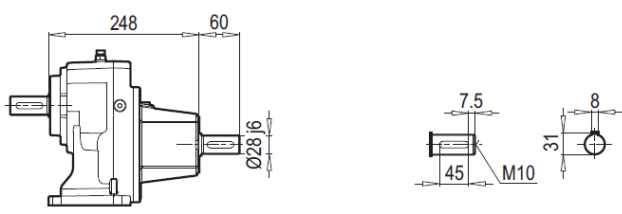

F 501 W
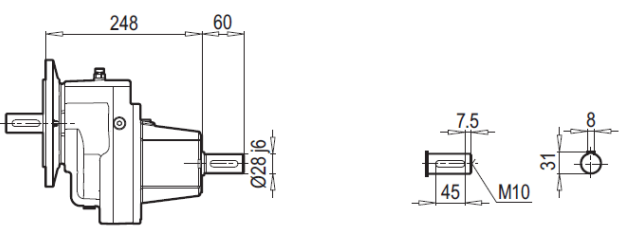

AF 501 W

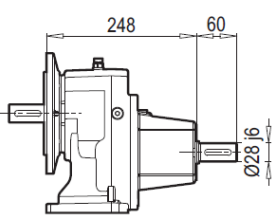

ma10

AF-M 501 W

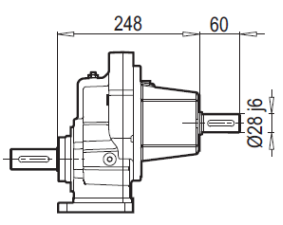

Fig. 18. Characteristic mounting ways of single-stage gear reducer (NRW solution) [5]. 
Single-stage gear reducer with free shaft arrangement, ie. shaft-mounted gear units are mounted directly to the driving shaft and the shaft position itself adapts to the specific mounting conditions (Fig. 19).
Using special mounts this position can be adapted to different positions and ways of mounting (Fig. 20), but these solutions are somewhat expensive than usual footmounted or flange-mounted solutions.

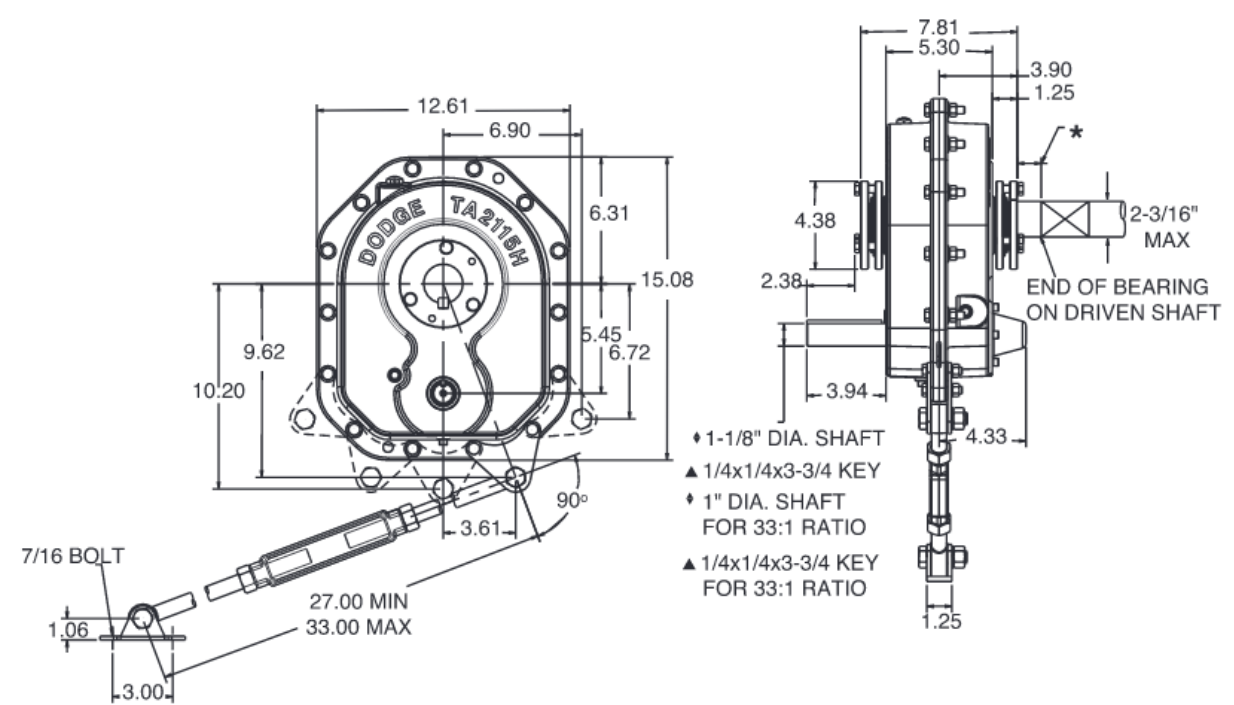

Fig. 19. Characteristic design solution of position and way of mounting of shaft-mounted single-stage gear reducer (Dodge solution) [19].
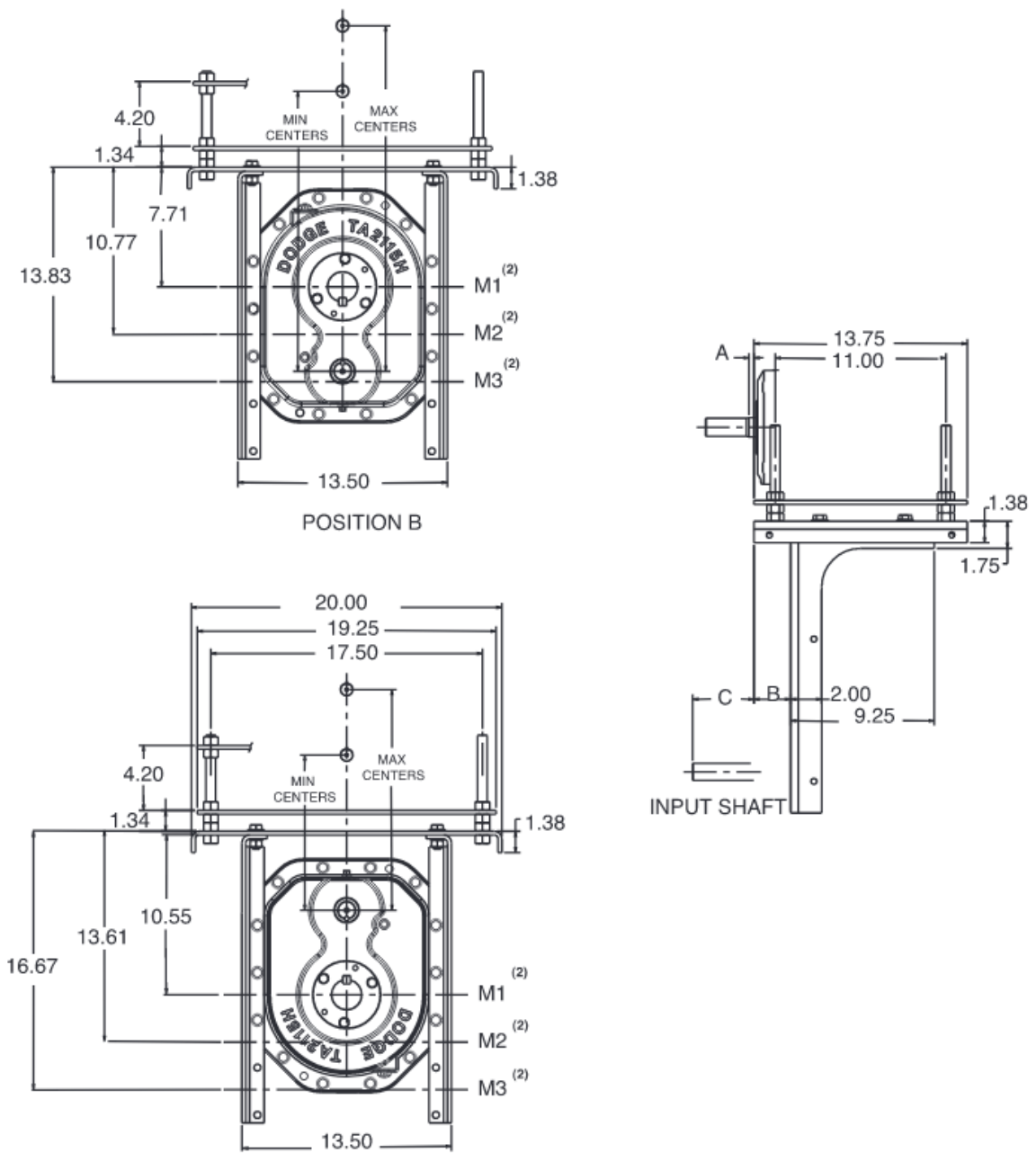

INPUT SHAFT

Fig. 20. Characteristic design solution of position and way of mounting of shaft-mounted single-stage gear reducer by using special mounts (Dodge solution) [19].

\footnotetext{
Corresponding author: racmil@uns.ac.rs
} 


\section{Expected design directions of further development}

Based on the performed design solutions of single-stage gear reducers produced by leading manufacturers of gear units, it can be concluded that further intensive development of all types of these reducers can be expected.

Gear reducer with horizontal shaft arrangement, with the housings with feet on all four sidewise surfaces and with connected flanges (Fig. 10 and 15) presents the most universal gear reducer. This type of reducer is adapted for all positions and ways of mounting, but at the same time, it is the most expensive due to extensive machine processing and the largest consumption of materials. Therefore, their intensive development could not be expected further, but they will be produced by an only small number of manufacturers to satisfy operating requirements.

Gear reducers with vertical shaft arrangement footmounted (Fig. 21), flange-mounted (Fig. 22) and foot and flange-mounted (Fig. 12) are probably the most basic positions of mounting that will be required in future due to relatively low production costs, suitable form and low cost of materials. Other forms are less required and they are produced by smaller manufacturers who want to cover the market segment which is not covered by large manufacturers.
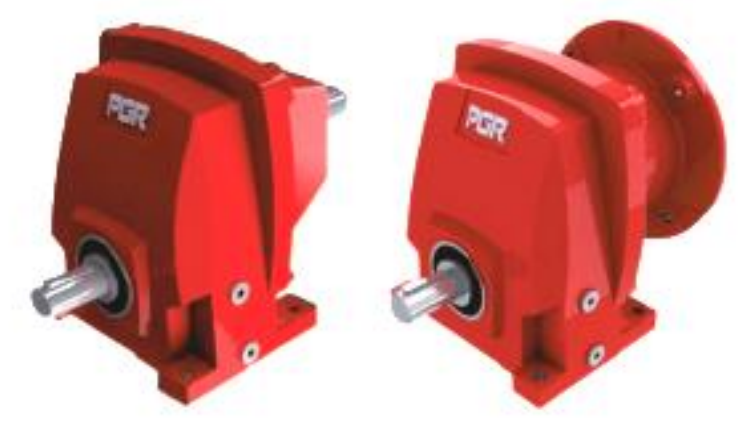

Fig. 21. Characteristic forms of foot-mounted single-stage gear reducer (PGR solution) [9].

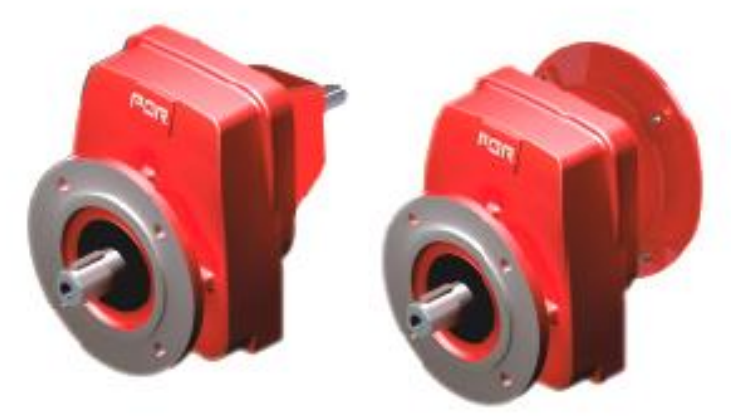

Fig. 22. Characteristic forms of flange-mounted single-stage gear reducer (PGR solution) [9].

Further intensive development of shaft-mounted single-stage gear reducers can be also expected. Their installation doesn't require flanges at the output shaft which provide cheaper construction. They provide a more compact and simpler construction since the classic gear foundation is not required, which is certainly a great advantage and a great reason for further development and application of these gear units.

\section{Conclusions}

It is evident that modern gear reducers, besides functional requirements, place aesthetic demands, regardless of material consumption and manufacturing complexity. No matter gear reducer is installed inside the machine and it is often not visible to the observer, its attractive form becomes very important. Since the gear reducers are nowadays quite uniform in quality, technical characteristics and price, special attention should be paid to the design of the gear units because a nice gearbox always attracts the attention of the customer who decides about its purchase. This conclusion follows by researching and observing derived gearbox solutions produced by world-leading manufacturers.

\section{References}

1. S. Kuzmanović, Universal gear reducers (FTN Novi Sad, 2009)

2. M. Rackov, Conceptions of Development of Universal Gear Reducers (PhD thesis in Serbian), (the University of Novi Sad, Faculty of Technical Sciences, 2013)

3. M. Rackov, S. Kuzmanović, M. Blagojević, Z. Đorđević, Motor Gear Reducers with Cylindrical Gears (Faculty of Technical Sciences, 2019)

4. SEW Helical gear motors, $21933189 / \mathrm{EN}-11 / 2015$

5. NRW Helical Geared Motors, K.No: A/F 03/2016

6. M. Rackov, S. Kuzmanović, Proposal of Assessment Method for the Conceptual Design of Universal Helical Gear Reducers, The 7th International Scientific Conference Research and Development of Mechanical Elements and Systems, 27-28 April 2011, Zlatibor, Serbia

7. M. Rackov, I. Knežević, S. Kuzmanović, M. Čavić, M. Penčić, Analysis of Housing Models of Modern Single-Stage Universal Gear Reducers, IOP Conference Series: MSE, Vol. 393, (IOP Publishing, Bristol, United Kingdom, 2018)

8. NORDBLOC.1® Helical In-Line Gear Units, $100200108 / 0517$

9. PGR Drive Technologies, Catalogue Helical Gear Units, PA/PF series 02/2017

10. Leroy Somer catalogue, Shaft mount speed reducer, 3780 en - 2017.06/e

11. Peerless-Winsmith, Inc, SE Encore Catalog, 2008

12. Lenze, L-force, Geared Motors, Effizient un passgenau, 01/2018, Version 1.2 de

13. Bonfiglioli Riduttori, S series, Single Stage Gearboxes, COD. 1044 R8, 120127, Bologna, Italy

Corresponding author: racmil@uns.ac.rs 
14. Kissling - The Gear Company, Catalog Helical and bevel-helical gear reducers

15. Flender gear units, Catalog MD 20.1-2009, Siemens $\mathrm{AG}$

16. Hansen P4 standardized heavy duty single stage gear units catalogue, DOC-CAM626E/0613

17. Rossi parallel shaft gear reducers catalogue, 004BRO.GPR-de1105HQR

18. STM TEAM catalogue, CT17 IGBD $3.1 \mid$ ITA ENG - DEU, 3/2016

19. https://www.rehfuss.com/de/ 